\title{
EL CAMINO DE LA VIDA, UN CAMINO DE SEGUIMIENTO PARA EL CRISTIANO DE HOY
}

DOI: https://doi.org/10.52039/seminarios.v61i214.172

\author{
María del Carmen Azaustre SerRano*
}

Al comenzar a escribir este artículo sobre el camino de la vida, me salen al encuentro estas palabras del poeta León Felipe, cuando dice: «Nadie fue ayer, / ni va hoy, / ni irá mañana / hacia Dios / por este mismo camino / que yo voy. / Para cada hombre guarda un rayo nuevo de luz el sol... / y un camino virgen / Dios» ${ }^{1}$.

Efectivamente el camino es recorrido por cada persona y tiene un sello original que imprime a su paso la fuerza que la mueve.

Los del "Camino» fue el primer nombre que recibieron los seguidores de Jesús de Nazaret, el de cristianos les fue dado por los paganos de Antioquía. Los seguidores entendieron las palabras de Jesús: «No estéis agitados; fiaos de Dios y fiaos de mí (...) Yo soy el camino, la verdad y la vida. Nadie se acerca al Padre sino por mí. Si me conocéis a mí, conoceréis también a mi padre, aunque ya desde ahora lo conocéis y lo estáis viendo» (Jn 14, 1-6).

Jesús se presenta como el Camino y también como la Verdad y la Vida. Hacer el camino supone un encuentro con Él y un seguimiento de su vida. Una nueva manera de ser y actuar. Y para ese obrar Jesús es también el foco, el faro que irradia la luz en esa navegación por un mar sereno o tempestuoso. Pero un mar en el que podemos oír esa palabra dicha a los suyos en medio de la tempestad, «Era ya noche cerrada y todavía Jesús no los había alcanzado; soplaba además un fuerte viento y el lago se iba encrespando. Habían remado unos cinco o seis kilómetros cuando vieron a Jesús que andaba por el lago acercándose a la barca y se asustaron; pero él les dijo: 'Soy yo, no tengáis miedo'» (Jn 6, 16-20).

Son estas mismas palabras las que fortalecen a Teresa de Jesús, peregrina del camino, en la lucha en que se debate para conocer si su experiencia, lo que siente, viene de Dios: «No hayas miedo, que yo soy. Tenían tanta fuerza estas palabras, que no lo podía dudar por entonces, y quedaba muy esforzada y alegre con tan buena compañía; que veía claro serle gran ayuda para andar con una ordinaria memoria de Dios y un miramiento grande de no hacer cosa que le desagradase, porque le parecía la estaba siempre mirando» $(6 \mathrm{M} 8,3)$.

* Doctora en Filología hispánica, profesora emérita del CEU «Cardenal Spínola» de Sevilla.

1. «Versos y oraciones del caminante», Poesías completas, Visor, Madrid 2010, 61. 
Para Teresa no hay otro camino para llegar al encuentro que la Humanidad de Jesucristo. Ha sufrido los argumentos de los que la contradicen: «Yo no puedo pensar en qué piensan; porque, apartados de todo lo corpóreo, para espíritus angélicos es estar siempre abrasados en amor, que no para los que vivimos en cuerpo mortal, que es menester trate y piense y se acompañe de los que, teniéndole, hicieron tan grandes hazañas por Dios; cuánto más apartarse de industria de todo nuestro bien y remedio que es la sacratísima Humanidad de nuestro Señor Jesucristo. $Y$ no puedo creer que lo hacen, sino que no se entienden, y así harán daño a sí y a los otros. Al menos yo les aseguro que no entren a estas dos moradas postreras; porque si pierden la guía, que es el buen Jesús, no acertarán el camino; harto será si se están en las demás con seguridad. Porque el mismo Señor dice que es camino; también dice el Señor que es luz, y que no puede ninguno ir al Padre sino por El; $y$ «quien me ve a mí ve a mi Padre». Dirán que se da otro sentido a estas palabras. Yo no sé esotros sentidos; con éste que siempre siente mi alma ser verdad, me ha ido muy bien $(6 \mathrm{M} 7,6)$.

Teresa siente su humanidad y, desde esa humanidad, se encuentra con aquellos, los del Camino, que a lo largo de la historia han sido comunicadores y referencia de evangelio. Anima a no perder la guía que es «el buen Jesús». Para Teresa, Jesús, la Humanidad de Jesucristo, es el camino.

En el camino de la vida, de la historia de los pueblos, hay también noches cerradas, olas que se levantan tumultuosas y empapan de frío y agua nuestros cuerpos ateridos, pero siempre podremos oír esa voz -para nosotros camino, verdad y vida- que nos despoja del miedo y del frío. El agua se convierte así en un agua viva que sacia nuestra sed. Porque sentimos en el interior las palabras que nos asientan en la certeza: «Yo soy la luz del mundo: el que me sigue no andará en tinieblas, tendrá la luz de la vida» (Jn 8, 12).

Jesús no es solo el camino, sino que es la luz, la luz de la vida para quienes lo siguen. Él camina a nuestro lado, aunque a veces nos debatamos en los sucesos que nos afectan, que nos tocan el corazón, y no nos demos cuenta de que aquel hombre que se cruzó con nosotros y nos acompañaba y nos explicaba las Escrituras era Jesús el Salvador. Aquel que se detuvo con nosotros y al que reconocimos en el compartir de una entrañable cena. Es su manera de regalar, de explicarnos con obras, con escasas palabras que ese compartir, esa fracción del pan es el signo de la hermandad y ese el mensaje que nos deja en la mañana en la que, aunque ya lo no percibamos, sentimos en el corazón el calor de su presencia que se perpetúa en el lazo estrecho de la hermandad que nos propone.

\section{TERESA DE JESÚS}

Hace quinientos años, una mujer, Doña Teresa de Ahumada, más tarde, en su conversión, Teresa de Jesús, proponía este camino de encuentro a quienes con ella se relacionaban. Una mujer que tuvo que vencer las dificultades que en 
el siglo XVI salpicaban su rostro de mujer, su origen judío converso que lanzaba sobre ella amenazas, su gran afán de lectora frente al analfabetismo existente, las dudas de los teólogos y espirituales sobre la capacidad de la mujer para adentrarse en el misterio de Dios, las dificultades que provenían de su cuerpo enfermo aunque lleno de energía interior, las que surgieron de esa palabra que la habitaba y la inducía al servicio y a una intensa actividad fundacional, a una radicalidad en el seguimiento de Jesús en aquella forma de vida a la que había sido llamada y que la impulsó a reformar la orden del Carmelo, para hacerla más conforme a la voluntad del Señor, su Majestad, su Emperador, como solía llamarle.

Toda la vida de Teresa es un ejemplo de seguimiento. En ella se cumple lo que decía al concluir uno de sus escritos cumbres, El castillo interior o las Moradas: «Mirad que importa esto mucho más que yo os sabré encarecer. Poned los ojos en el Crucificado y haráseos todo poco. Si Su Majestad nos mostró el amor con tan espantables obras y tormentos, ¿cómo queréis contentarle con sólo palabras? ¿Sabéis qué es ser espirituales de veras? Hacerse esclavos de Dios, a quien, señalados con su hierro que es el de la cruz, porque ya ellos le han dado su libertad, los pueda vender por esclavos de todo el mundo, como Él lo fue; que no les hace ningún agravio ni pequeña merced. Y si a esto no se determinan, no hayan miedo que aprovechen mucho, porque todo este edificio -como he dicho- es su cimiento humildad; y si no hay ésta muy de veras, aun por vuestro bien no querrá el Señor subirle muy alto, porque no dé todo en el suelo. Así que, hermanas, para que lleve buenos cimientos, procurad ser la menor de todas y esclava suya, mirando cómo o por dónde las podéis hacer placer y servir; pues lo que hiciereis en este caso, hacéis más por vos que por ellas, poniendo piedras tan firmes, que no se os caiga el castillo» $(7 \mathrm{M} 4,8)$.

Teresa señala aquí dónde reside la espiritualidad del seguimiento de Jesús, un seguimiento que se apoya y se funda en la mirada al Crucificado que es el que nos enseña el signo de su amor, amor a amigos y a enemigos. Una espiritualidad que se sustenta en el servicio y una espiritualidad buscada en el empeño de una fuerte determinación, de una firme voluntad en este seguir a Jesús, donde uno de sus cimientos es la humildad. La humildad que para Teresa es la verdad. Una firmeza que hará descansar nuestro edificio en la roca.

Por ello, Teresa sigue diciendo: «Para esto es la oración, hijas mías; de esto sirve este matrimonio espiritual: de que nazcan siempre obras» $(7 \mathrm{M} 4,6)$. Vemos aparecer aquí un vocablo que para Teresa es fundamental en esta imitación de Cristo: el de «oración». Porque la oración es para ella diálogo de amistad con quien sabemos nos ama y en este diálogo receptor y comunicante van haciéndose uno con un fin, el servicio: «Esto quiero yo, mis hermanas, que procuremos alcanzar, y no para gozar, sino para tener estas fuerzas para servir: deseemos y nos ocupemos en la oración; no queramos ir por camino no andado, que nos perderemos al mejor tiempo; y sería bien nuevo pensar tener estas mercedes de Dios por otro que el que Él fue y han ido todos sus santos; no nos pase por 
pensamiento; creedme, que Marta y María han de andar juntas para hospedar al Señor y tenerle siempre consigo, y no le hacer mal hospedaje no le dando de comer. ¿Cómo se lo diera María, sentada siempre a sus pies, si su hermana no le ayudara? Su manjar es que de todas las maneras que pudiéremos lleguemos almas para que se salven y siempre le alaben» $(7 \mathrm{M} 4,12)$.

Una oración que prepara para el servicio, para la acogida. Una oración que es diálogo de amistad que prepara y lleva al encuentro con los otros. Una oración que lleva primero al encuentro con los cercanos, con lo pequeño. Porque a veces se nos ponen deseos de hacer cosas grandes y dejamos de hacer las pequeñas y sencillas, las que tenemos al alcance de la mano por desear las imposibles: «Es cosa que creo os pasa por pensamiento, con los deseos que os da el Señor, no dejaré de decirlo aquí: ya os dije en otra parte que algunas veces nos pone el demonio deseos grandes, porque no echemos mano de lo que tenemos a mano para servir a nuestro Señor en cosas posibles, y quedemos contentas con haber deseado las imposibles. Dejado que en la oración ayudaréis mucho, no queráis aprovechar a todo el mundo, sino a las que están en vuestra compañía, y así será mayor la obra, porque estáis a ellas más obligadas» $(7 \mathrm{M} 4,14)$.

Estas obras irán siempre acompañadas de amor, mucho amor porque «el Señor no mira tanto la grandeza de las obras como el amor con que se hacen; y como hagamos lo que pudiéremos, hará Su Majestad que vayamos pudiendo cada día más y más, como no nos cansemos luego, sino que lo poco que dura esta vida -y quizá será más poco de lo que cada una piensa- interior y exteriormente ofrezcamos al Señor el sacrificio que pudiéremos, que Su Majestad le juntará con el que hizo en la cruz por nosotras al Padre, para que tenga el valor que nuestra voluntad hubiere merecido, aunque sean pequeñas las obras» $(7 \mathrm{M} 4,15)$.

Amor, actuación posible, ensanchamiento de la capacidad de obrar, constancia y unión con el valor incalculable de la salvación de Dios serán los fundamentos de estas altas torres.

\section{EL MAGISTERIO DE TERESA}

El 28 de marzo de 2015, el papa Francisco escribió una carta al Rvdmo. P. Saverio Cannistrà, Prepósito general de la Orden de los Hermanos Descalzos de la Bienaventurada Virgen María del Monte Carmelo, en la que nombra a Teresa como una mujer excepcional, como guía segura y atrayente para los hombres y mujeres de este siglo, y expresa cómo sigue haciendo bien hoy el testimonio de su entrega que nace «directamente del encuentro con Cristo, su experiencia de oración, como diálogo continuo con Dios, y su vivencia comunitaria, enraizada en la maternidad de la Iglesia»².

2. Carta del papa Francisco al Rvdmo. Padre Severio Cannistrá, Prepósito general de la Orden de los Hermanos Descalzos de la Bienaventurada Virgen María del Monte Carmelo, 28 de marzo de 2015. Puede leerse dicha carta en la sección «Documentos» de esta revista. 
La presenta ante todo como maestra de oración y pone como punto central de su experiencia su descubrimiento de la humanidad de Cristo: «Movida por el deseo de compartir esa experiencia personal con los demás, escribe sobre ella de una forma vital y sencilla, al alcance de todos, pues consiste simplemente en 'tratar de amistad con quien sabemos nos ama'(Vida 8, 5). Muchas veces la misma narración se convierte en plegaria, como si quisiera introducir al lector en su diálogo interior con Cristo» ${ }^{3}$.

Sugiere cómo la oración de Teresa «no fue una oración reservada únicamente a un espacio o momento del día»; surgía espontánea en las ocasiones más variadas: "Cosa recia sería que solo en los rincones se pudiera traer oración» (Fundaciones 5, 16). Estaba convencida del valor de la oración continua, aunque no fuera siempre perfecta. La Santa nos pide que seamos perseverantes, fieles, incluso en medio de la sequedad, de las dificultades personales o de las necesidades apremiantes que nos reclaman ${ }^{4}$.

Y explicita cómo «a partir de su encuentro con Jesucristo, Santa Teresa vivió 'otra vida'; se convirtió en una comunicadora incansable del Evangelio (cf. Vida $23,1) »$. Deseosa de servir a la Iglesia, y a la vista de los graves problemas de su tiempo, no se limitó a ser una espectadora de la realidad que la rodeaba. Desde su condición de mujer y con sus limitaciones de salud, decidió - dice ella- «hacer eso poquito que era en mí, que es seguir los consejos evangélicos con toda la perfección que yo pudiese y procurar que estas poquitas que están aquí hiciesen lo mismo» (Camino 1, 2). Por eso comenzó la reforma teresiana, en la que pedía a sus hermanas que no gastasen el tiempo tratando «con Dios negocios de poca importancia» cuando estaba «ardiendo el mundo» (Camino 1, 5) 5 .

El papa Francisco plantea la actualidad de su mensaje hoy porque «también hoy la Santa nos abre nuevos horizontes, nos convoca a una gran empresa, a ver el mundo con los ojos de Cristo, para buscar lo que Él busca y amar lo que Él ama».

Teresa es, efectivamente, una gran maestra. Doctora Honoris Causa la reconoció la Universidad de Salamanca en el aniversario de su canonización, en sesión de claustro del 4 de marzo de 1922. Se celebró dicha concesión en solemne acto el 6 de octubre de 1922, presidido por los reyes Alfonso XIII y Victoria Eugenia. Años más tarde, en 1970, fue reconocida como doctora de la Iglesia por el papa Pablo VI.

Su magisterio es indiscutible y aunque ella misma se considera mujer no letrada su formación se extendió a lo largo de toda su vida. Lecturas, diálogos con eminentes teólogos, y, sobre todo su experiencia de libro vivo que fue Jesús para Teresa.

3. Ibid.
4. Ibid.
5. Ibid. 


\section{Lecturas de Teresa}

Teresa fue muy aficionada a leer desde sus primeros años. En su infancia, las vidas de santos, a través del Flos Sanctorum, traducción de la Leyenda áurea de Giacomo da Varazze; más tarde, lecturas de otro género, Los libros de caballerías. Libros que leía en compañía de su madre, a hurtadillas de su padre que no quería esas lecturas para su hija. Después, cuando se opera en su vida un profundo cambio, esa favorable actitud que ya tenía para la lectura, le hace introducirse en otros autores que cambian su vida. Estas son algunas de las lecturas de Teresa en momentos importantes de su vida: Primero, las Cartas de san Jerónimo: «Dióme la vida haber quedado ya amiga de buenos libros. Leía en las Epístolas de San Jerónimo, que me animaban» (V 3, 7).

Después, los Morales de San Gregorio que comentan el libro de Job: «Me espanto, y tengo por gran merced del Señor la paciencia que Su Majestad me dio, que se veía claro venir de Él. Mucho me aprovechó para tenerla haber leído la historia de Job en los Morales de San Gregorio, que parece previno el Señor con esto, y con haber comenzado a tener oración, para que yo lo pudiese llevar con tanta conformidad. Todas mis pláticas eran con Él. Traía muy ordinario estas palabras de Job en el pensamiento y decíalas: Pues recibimos los bienes de la mano del Señor, ¿por qué no sufriremos los males? Esto parece me ponía esfuerzo».

Ella misma nos narra en el libro de la Vida como era muy aficionada a san Agustín porque estuvo en ese monasterio cuando era seglar y porque era un pecador que había vuelto a Dios «que en los santos que después de serlo el Señor tornó a sí, hallaba yo mucho consuelo» ( $\mathrm{V} 9,7)$.

Pero es en la lectura de las Confesiones, a sus 39 años de edad, donde declara su identificación con él y donde siente la misma voz que obró en él la conversión: «En este tiempo me dieron las Confesiones de San Agustín, que parece el Señor lo ordenó, porque yo no las procuré ni nunca las había visto. Yo soy muy aficionada a San Agustín, porque el monasterio adonde estuve seglar era de su Orden y también por haber sido pecador, que en los santos que después de serlo el Señor tornó a Sí hallaba yo mucho consuelo, pareciéndome en ellos había de hallar ayuda y que como los había el Señor perdonado, podía hacer a mí; salvo que una cosa me desconsolaba, como he dicho, que a ellos sola una vez los había el Señor llamado y no tornaban a caer, y a mí eran ya tantas, que esto me fatigaba. Mas considerando en el amor que me tenía, tornaba a animarme, que de su misericordia jamás desconfié. De mí muchas veces».

Junto a estas, los Evangelios: "Siempre yo he sido aficionada y me han recogido más las palabras de los Evangelios, que se salieron por aquella sacratísima boca así como las decía, que libros muy bien concertados» (CE 35, 4).

A los que sumamos La Vita Christi de Rodolfo de Sajonia o Cartujano, quizá en la traducción de Fray Ambrosio Montesinos en 1520; el Contemptus mundi, traducido por Fray Luis de Granada; El Arte de servir a Dios (1521) de Fray Alonso 
de Madrid. Teresa cuando habla de los principiantes en la oración lo recomienda: «Puede en este estado hacer muchos actos para determinarse a hacer mucho por Dios y despertar el amor, otros para ayudar a crecer las virtudes, conforme a lo que dice un libro llamado Arte de servir a Dios, que es muy bueno y apropiado para los que están en este estado, porque obra el entendimiento» $(\mathrm{V} 12,2)$.

$Y$ el que fue para ella su «maestro»: El tercer abecedario, de Francisco de Osuna, y al que califica como buen libro, buena lectura con las anteriores y con el que disfrutó y comenzó su camino de conversión: «Cuando iba, me dio aquel tío mío que tengo dicho que estaba en el camino, un libro: llámase Tercer Abecedario, que trata de enseñar oración de recogimiento; y puesto que este primer año había leído buenos libros (que no quise más usar de otros, porque ya entendía el daño que me habían hecho), no sabía cómo proceder en oración ni cómo recogerme, y así holgueme mucho con él y determineme a seguir aquel camino con todas mis fuerzas. Y como ya el Señor me había dado don de lágrimas y gustaba de leer, comencé a tener ratos de soledad y a confesarme a menudo y comenzar aquel camino, teniendo a aquel libro por maestro» $(\vee 4,7)$.

También podemos citar La subida del Monte Sion de Bernardino de Laredo (Sevilla, 1535).

Teresa desea una buena formación para las monjas de sus conventos y son estas lecturas las que recomienda en las Constituciones para que se incluyan en sus conventos: «Tenga cuenta la priora con que haya buenos libros, en especial Cartujanos, Flos Sanctorum, Contemptus Mundi, Oratorio de Religiosos (de Fray Antonio de Guevara), los de fray Luis de Granada (Guía de pecadores y libro de la oración) y del padre fray Pedro de Alcántara; porque es en parte tan necesario este mantenimiento para el alma, como el comer para el cuerpo» ${ }^{6}$.

\section{SU PROPUESTA: CAMINO DE PERFECCIÓN}

Teresa redacta este libro en 1566, a sus 51 años de edad, bajo la orientación crítica de Fray Domingo Báñez, por entonces su confesor. Así expresa su finalidad y las causas que le llevan a escribirlo: «Para escribir algunas cosas de oración en que parece podré atinar por haber tratado con muchas personas espirituales y santas» (CV Prólogo); «Me han tanto importunado les diga algo de ella, que me he determinado a las obedecer, viendo que el amor grande que me tienen puede hacer más acepto lo imperfecto y por mal estilo que yo les dijere, que algunos libros que están muy bien escritos de quien sabía lo que escribe» (ibid.).

E indica cuál es su actitud ante este mandato, el amor: «Sé que no falta el amor y deseo en mí para ayudar en lo que yo pudiere para que las almas de mis hermanas vayan muy adelante en el servicio del Señor. Y este amor, junto con los años y experiencia que tengo de algunos monasterios, podrá ser aproveche

6. Constituciones, en Obras completas de Santa Teresa de Jesús, Madrid ${ }^{3} 1984,1136$. 
para atinar en cosas menudas más que los letrados, que por tener otras ocupaciones más importantes y ser varones fuertes no hacen tanto caso de cosas que en sí no parecen nada, y a cosa tan flaca como somos las mujeres todo nos puede dañar» (ibid.).

Es el deseo de ayudar a las que han emprendido un camino de seguimiento el que le hace escribir y poner la intensidad en lo pequeño, porque por experiencia sabe el daño que puede producir no dar importancia a las cosas menudas.

Es un libro dedicado a mujeres y, en especial, a las «hermanas» de San José de Ávila. Tuvo varias redacciones -la Santa lo escribió dos veces-y corrió manuscrita hasta que fue publicado por primera vez en Évora en 1583. Teresa, en carta que escribe a D. Teutonio de Braganza, arzobispo de Evora y gran amigo suyo, el 22 de julio de 1579, le dice que la semana anterior le escribió y le envió «el librillo» junto con la vida de san Alberto «que va en un cuadernillo en el mismo libro» para que él los mandase imprimir juntos.

Diversas circunstancias hicieron que esta obra no se publicara hasta un año después de su muerte.

En la excelente introducción que precede a la edición de Camino de perfección (Madrid 2008), José Vicente Rodríguez, carmelita descalzo, llama la atención sobre el hecho del título del libro ya que ni una sola vez se encuentra esta expresión en la obra, ni en CE ni en CV, aunque sí nota cómo en las copias de Salamanca, Madrid y Toledo, revisadas por la Santa, se le llama Camino de perfección, aunque en Vida sí aparece esta denominación para aplicarla a las personas que han iniciado el seguimiento de Jesús.

La obra consta de 42 capítulos. Los cuatro primeros hablan del fin de su reforma: Teresa conoce los sucesos acaecidos en Francia y las rupturas y dificultades de la Iglesia allí: «En este tiempo vinieron a mi noticia los daños de Francia y el estrago que habían hecho los Luteranos». Se sabe mujer, débil y quiere hacer lo poco que ella puede hacer «determiné a hacer eso poquito que era en mí, que es seguir los consejos evangélicos con toda la perfección que yo pudiese». Presenta a todos la difícil situación histórica: «Se está ardiendo el mundo, quieren tornar a sentenciar a Cristo -como dicen-, pues le levantan mil testimonios, quieren poner su Iglesia por los suelos (...) No, hermanas mías, no es tiempo de tratar con Dios negocios de poca importancia».

Ante la situación eclesial que conoce y vive, siente que hay que orar «por los capitanes de este castillito». Capitanes que son los predicadores y teólogos para que «vayan muy adelante en su perfección y llamamiento». Porque sabe que el contacto con el mundo los puede hacer retroceder en su camino de perfección: «¿Pensáis, hijas mías, que es menester poco para tratar con el mundo y vivir en el mundo y tratar negocios del mundo y hacerse -como he dicho- a la conversación del mundo y ser en lo interior extraños del mundo y enemigos del mundo y estar como quien está en destierro y, en fin, no ser hombres sino ángeles? Porque, a no ser esto así, ni merecen nombre de capitanes, ni permita el Señor 
salgan de sus celdas, que más daño hará que provecho; porque no es ahora tiempo de ver imperfecciones en los que han de enseñar» (CV 3, 3).

Y para ello pide a sus monjas que vivan con radicalidad los consejos evangélicos para que merezcan alcanzar de Dios que haya muchos y santos teólogos y confesores y a los que no lo sean que Dios los convierta que «más hará uno perfecto que muchos que no lo estén». Les dice también que recen por ellos «para que puedan librarse de tantos peligros como hay en el mundo y tapar los oídos en este peligroso mar del canto de las sirenas».

Y para ello, para preparar este camino de la oración que les pide, les ofrece tres actitudes básicas para comenzarlo: «La una es amor unas con otras; otra, desasimiento de todo lo criado; la otra, verdadera humildad, que, aunque la digo a la postre, es la principal y las abraza todas» $(\mathrm{CV} 4,4)$.

Estas actitudes son los presupuestos básicos para comenzar este camino de oración. Dichas actitudes las desarrolla en los capítulos cuatro al dieciséis. Del dieciséis al cuarenta y dos trata de la vida de oración y de la oración por excelencia, el Padrenuestro.

\section{UN CAMINO PARA TODOS}

¿Por qué nos parece que esta propuesta que Teresa hace en Camino es para todos? La respuesta es sencilla y viene de la misma pluma de Teresa, porque aunque ella en su prólogo lo dedica a sus hermanas descalzas, a lo largo del libro lo propone como camino de oración y perfección válido para cualquier cristiano: «Mirad que convida el Señor a todos. Pues es la misma verdad, no hay que dudar. Si no fuera general este convite, no nos llamara el Señor a todos, y aunque los llamara, no dijera: 'Yo os daré de beber'. Pudiera decir: 'Venid todos, que, en fin, no perderéis nada; y los que a mí me pareciere, yo los daré de beber»'. Mas como dijo, sin esta condición, 'a todos', tengo por cierto que todos los que no se quedaren en el camino, no les faltará esta agua viva» (CV 19, 15).

El camino que Teresa propone está dirigido a todos los cristianos, sin limitaciones y es el camino de la oración que abre la puerta de ese castillo interior donde Dios tiene su centro y camino al que invita a todos en un precioso diálogo de amistad.

Teresa es consciente de que dirige su propuesta a «entendimientos tan desbaratados como unos caballos desbocados, que no hay quien los haga parar. Ya van aquí, ya van allí, siempre con desasosiego» (CV 19, 2).

Pero hay almas sedientas de Dios que alguna vez probaron de su agua viva y les faltó ánimo para seguir. A este grupo de personas las anima diciéndoles que les muestra primero el gran bien que han de alcanzar para que no «se acongojen del trabajo y contradicción que hay en el camino" y vayan con ánimo y no se cansen porque, «como es tan bueno, no nos fuerza, antes da de muchas maneras a beber a los que le quieren seguir, para que ninguno vaya desconsolado ni muera 
de sed. Porque de esta fuente caudalosa salen arroyos, unos grandes y otros pequeños, y algunas veces charquitos para niños, que aquello les basta, y más sería espantarlos ver mucha agua; éstos son los que están en los principios. Así que, hermanas, no hayáis miedo muráis de sed en este camino» ( $\vee 20,2)$.

Ella es consciente de que aunque vayamos caminando el polvo del camino nos puede cegar y es necesaria la luz que en este camino de oración va capacitando y ensanchando el alma.

Anima a no quedarse en el camino, sino a pelear como fuertes hasta morir en la demanda, porque está presente en el alma una fuerte determinación, la de no dejar este camino y anima a sus hijas a que a todas las personas que trataren las lleven por este camino de la oración: «Habiendo disposición y alguna amistad procurad quitarlas el miedo de comenzar tan gran bien (...) Si queréis ser buen deudo esta es la verdadera amistad; si buena amiga, entended que no podéis ser, sino por este camino. Ande la verdad en vuestros corazones (...) No es ya tiempo, hermanas, de juego de niños» ( $V$ 20, 3-4).

Y a continuación pone el acento en una firme decisión de seguir el camino: «Ahora, tornando a los que quieren ir por él y no parar hasta el fin, que es llegar a beber de esta agua de vida, cómo han de comenzar, digo que importa mucho, y el todo, una grande y muy determinada determinación de no parar hasta llegar a ella, venga lo que viniere, suceda lo que sucediere, trabájese lo que se trabajare, murmure quien murmurare, siquiera llegue allá, siquiera se muera en el camino o no tenga corazón para los trabajos que hay en él, siquiera se hunda el mundo» (V 21, 2).

Teresa impulsa al inicio de este camino de diálogo con un Señor que siempre habla al corazón, aunque creamos que está callado. Y anima a hacer la oración mental que lleva "pensar y entender qué hablamos y con quién hablamos y quién somos los que osamos hablar con tan gran Señor. Pensar esto y otras cosas semejantes de lo poco que le hemos servido y lo mucho que estamos obligados a servir es oración mental» (CV 25, 3).

Y va dando los recursos para comenzar este tipo de oración: «Procurad luego, hija, pues estáis sola, tener compañía. Pues ¿qué mejor que la del mismo maestro que enseñó la oración que vais a rezar? Representad al mismo Señor junto con vos y mirad con qué amor y humildad os está enseñando. Y creedme, mientras pudiereis no estéis sin tan buen amigo. Si os acostumbráis a traerle cabe vos y Él ve que lo hacéis con amor y que andáis procurando contentarle, no le podréis -como dicen- echar de vos; no os faltará para siempre; ayudaros ha en todos vuestros trabajos; tenerle heis en todas partes: ¿pensáis que es poco un tal amigo al lado?» (CV 26, 1).

Y continúa explicando cuál debe de ser la actitud para los que comienzan este camino, mirar al Señor: «No os pido ahora que penséis en Él ni que saquéis muchos conceptos ni que hagáis grandes y delicadas consideraciones con vuestro entendimiento; no os pido más de que le miréis» (CV 26, 3). 
Expresa Teresa cómo la contemplación de los misterios de la vida de Jesús puede ayudarnos a expresar nuestras propias emociones y sentimientos de dolor o alegría.

Esta es la gran propuesta que el camino nos hace: recorrerlo con Jesús, mirarlo con la mirada de Jesús, hacer de nuestra vida una imitación de la suya: "Juntos andemos, Señor. Por donde fuereis, tengo de ir. Por donde pasareis, tengo de pasar» (CV 26, 6).

La propuesta de Teresa es una propuesta de amor que impregna todo lo que toca y, por tanto ama todo lo que Dios quiere y esta es la razón de su vivir, aunque a veces desee morir para hacer próximo el encuentro.

Para concluir quisiera citar estas palabras de Teresa: «iCómo me he alargado! Pues no tanto como quisiera, porque es cosa sabrosa hablar en tal amor. ¿Qué será tenerle? El Señor me le dé, por quien Su Majestad es» (CV 41, 1). 